University of Nebraska - Lincoln

DigitalCommons@University of Nebraska - Lincoln

\title{
Effect of Airflow on House Fly (Diptera: Muscidae) Distribution in Poultry Houses
}

Christopher Geden

USDA-ARS, Chris.geden@ars.usda.gov

Jerome Hogsette

USDA-ARS, Jerry.Hogsette@ars.usda.gov

Roger Jacobs

USDA-ARS

Follow this and additional works at: https://digitalcommons.unl.edu/usdaarsfacpub

Part of the Agricultural Science Commons

Geden, Christopher; Hogsette, Jerome; and Jacobs, Roger, "Effect of Airflow on House Fly (Diptera: Muscidae) Distribution in Poultry Houses" (1999). Publications from USDA-ARS / UNL Faculty. 1011. https://digitalcommons.unl.edu/usdaarsfacpub/1011

This Article is brought to you for free and open access by the U.S. Department of Agriculture: Agricultural Research Service, Lincoln, Nebraska at DigitalCommons@University of Nebraska - Lincoln. It has been accepted for inclusion in Publications from USDA-ARS / UNL Faculty by an authorized administrator of DigitalCommons@University of Nebraska - Lincoln. 


\title{
Effect of Airflow on House Fly (Diptera: Muscidae) Distribution in Poultry Houses
}

\author{
CHRISTOPHER J. GEDEN, JEROME A. HOGSETTE, AND ROGER D. JACOBS ${ }^{1}$
}

Center for Medical, Agricultural and Veterinary Entomology, USDA-ARS, P.O. Box 14565, Gainesville, FL 32604

J. Econ. Entomol. 92(2): 416-420 (1999)

\begin{abstract}
Numbers of fecal and vomit spots deposited by house flies, Musca domestica L., on spot cards were about twice as high on cards placed on the downwind sides as on the upwind sides of building support posts in caged-layer poultry houses with tunnel ventilation in Brooksville, FL. This trend was stronger at the ends of the houses where airflow is faster than in the relatively still-air center of the houses. A similar evaluation conducted in a pullet house (Zephyrhills, FL) with an evaporative cooling ventilation system revealed significantly higher fly counts on spot cards and sticky cards in downwind compared with upwind orientations. Flies in the pullet house were concentrated in both ends of the house and in the center, with comparatively fewer flies in the intermediate regions. There was a high degree of correlation between spot card and sticky card counts in the pullet house.
\end{abstract}

KEY WORDS Musca domestica, sampling, sticky card, poultry, airflow, spatial distribution

THE ECOLOGICAL FACTORS affecting distribution patterns of adult house flies, Musca domestica L., in animal confinement facilities are, for the most part, unknown. Studies have been conducted to evaluate the relative utility and efficiency of different fly sampling methods (Axtell 1970; Beck and Turner 1985; Lysyk and Axtell 1985, 1986; Stafford et al. 1988; Geden et al. 1992), but little is known about why flies tend to be more abundant in one location than in another. Stafford et al. (1988) reported substantially higher visual counts of flies resting on posts than on walls in high-rise poultry houses in Pennsylvania, and Burg and Axtell (1984) found that baited jug traps tended to catch more flies when positioned close to the manure surface. In opensided California-style poultry houses, spot cards attached to feed troughs were more sensitive to house fly population changes than cards attached to building rafters (Lysyk and Axtell 1985), and UV light traps, like the baited jug traps, captured more flies when hung just above the manure surface (Driggers 1971).

Unlike the open-sided houses used in many of the previously mentioned studies, most modern commercial pullet and cage-layer facilities are essentially closed to the outside elements. Temperature inside is regulated by several methods of forced-air ventilation systems that create distinct airflow patterns within the houses when fans are in operation. In many high-rise poultry houses, air enters the houses through evaporative cooling pads, which cool and add water to the air. There has been a trend in recent years for evaporative cooling systems to be superseded by tunnel ventilation systems, in which ambient air enters the

\footnotetext{
${ }^{1}$ Department of Dairy and Poultry Science, Institute of Food and Agricultural Sciences, University of Florida, Gainesville, FL 32611.
}

houses at high velocity through openings previously used for evaporative cooling pads. Ventilation systems also can be redesigned to allow increased airflow over the manure surface to facilitate drying. For example, curtains sometimes are placed at intervals in the manure pit perpendicular to airflow to keep the air movement in the pit as close to the manure surface as possible.

From casual observations that we made in houses with both tunnel ventilation or evaporative cooling systems, it appeared that flies preferred to rest on the downwind sides of building support posts (i.e., out of direct airflow). If house fly orientation and distribution are influenced by airflow, manipulation of airflow could be used to improve fly management programs. The objectives of our study were to determine whether airflow influenced the orientation and distribution of house flies in closed poultry houses, and to determine whether there is a correlation between fly counts by using spot cards (Axtell 1970) and sticky cards (Hogsette et al. 1993). These parameters were estimated by placement of spot cards and sticky cards on upwind and downwind sides of support posts in predetermined areas of the manure pits.

\section{Materials and Methods}

Tests were conducted from 1994 to 1995 on 2 Florida poultry farms representative of tunnel and evaporative cooling types of ventilation systems. The tunnel ventilation site, located near Brooksville, consisted of 3 high-rise caged layer houses. Each house (192 by $18 \mathrm{~m}$ ) housed $\approx 100,000$ hens. There were 4 rows of support posts in the manure pit parallel to the long axis of each house, with the posts within rows separated by 
Table 1. Average number of house fly spots per card per week during 41 wk of sampling on upwind and downwind sides of support posts in 3 sections of 2 poultry houses near Brooksville, FL, 1994-1995

\begin{tabular}{|c|c|c|c|c|c|}
\hline \multirow[t]{2}{*}{ Section } & \multicolumn{2}{|c|}{$\begin{array}{l}\text { Mean (SE) spots/card/wk } \\
\text { at orientation relative to airflow }\end{array}$} & \multicolumn{3}{|c|}{ ANOVA $F^{a}$} \\
\hline & Upwind & Downwind & Orientation & Date & Orientation $\times$ date \\
\hline \multicolumn{6}{|c|}{ House 1} \\
\hline South end & $74.4(9.04)$ & $171.2(21.26)$ & $14.61^{* *}$ & $10.22 * *$ & $2.46^{* * *}$ \\
\hline Center & $125.0(10.74)$ & $141.6(10.40)$ & $0.43 \mathrm{~ns}$ & $13.77^{* *}$ & $0.39 \mathrm{~ns}$ \\
\hline North end & $113.2(14.08)$ & $200.0(25.81)$ & $14.88^{* *}$ & $8.09 * *$ & $1.00 \mathrm{~ns}$ \\
\hline \multicolumn{6}{|c|}{ House 2} \\
\hline South end & $66.2(9.02)$ & $106.0(13.84)$ & $12.89^{* *}$ & $13.29 * *$ & $1.14 \mathrm{~ns}$ \\
\hline Center & $66.0(4.16)$ & $98.6(6.10)$ & $49.44^{* *}$ & $27.83 * *$ & $1.57^{*}$ \\
\hline North end & $45.0(5.94)$ & $83.0(12.60)$ & $6.42^{*}$ & $6.81^{* *}$ & $1.90 * *$ \\
\hline
\end{tabular}

${ }^{a} \mathrm{df}=40,328$ for date and date $\times$ orientation. The $F$ for orientation was calculated using the date $\times$ orientation mean square in the denominator if the interaction term was significant at $P=0.05(\mathrm{df}=1,40)$; otherwise the error mean square was used to calculate the orientation $F(\mathrm{df}=1,328)$ (Sokal and Rohlf 1981). ns, not significant; * $P<0.05$; **, $P<0.01$.

$2.9 \mathrm{~m}$. Four curtains located in the pit of each house functioned as wind baffles and divided the pit into 5 sections. Sections $1,2,4$, and 5 were similar in size (30-35 m long) but section 3 (the center) was approximately twice the size of each of the other sections. Air was drawn in through openings located on both floors of both ends of the houses and was vented outside by 2 banks of 12 exhaust fans located on the opposing walls of the sides of the houses in section 3. The wind shear caused by the opposing banks of exhaust fans created a zone of relatively still air in the center of section 3 compared with the 2 ends of the houses through which air entered. Air velocity in the houses (not measured in this study) could be controlled by regulating the number of fans in operation and by raising or lowering the curtains covering the ends of the houses. Curtains in the pit were raised as the manure accumulated so that the lower edge of the curtain was $5-15 \mathrm{~cm}$ above the manure surface.

Two houses were selected for the evaluation, designated as house 1 and house 2. Manure had accumulated for 2 and 4 mo before the study in houses 1 and 2 , respectively. In each house, white index cards (12.7 by $7.6 \mathrm{~cm}$ ) (spot cards) (Axtell 1970) were placed on the upwind and downwind sides of posts $1.5 \mathrm{~m}$ off the ground, with 5 posts selected from each of 3 regions of the houses; center (section 3), south end (section 1), and north end (section 5). Spot cards were placed initially on 10 May 1994 and changed weekly through 6 December. Sampling resumed on 6 February 1995 and continued on a biweekly basis through 15 June 1995 , at which time the manure was removed from the houses. In total, flies were sampled on 41 wk over a 13-mo period.

Spot card data from the 3 sections in each house were subjected to 2-way analysis analysis of variance (ANOVA) (SAS Institute 1987) by using orientation to airflow and sampling date as the main effects in the model. Orientation was treated as a fixed effect in the ANOVA and sampling date as a random effect. The $F$ values for sampling date and the interaction term were constructed using the error mean square in the de- nominator. Orientation was tested over the interaction mean square if $F$ for the latter was significant at $P=0.05$; the error mean square was used if the interaction was not significant (Sokal and Rohlf 1981). To evaluate whether fly density had an effect on orientation patterns, data from the ends of both houses were pooled and partitioned into high- and low-density posts, where high density was defined as posts whose total (upwind + downwind) spot card counts exceeded 100 spots. The ratio of downwind to upwind spot card counts was then calculated for each post, and an ANOVA was conducted to determine whether this ratio varied as a function of fly density.

The 2nd study site was a pullet house with an evaporative cooling system at a farm near Zephyrhills as described in Hogsette et al. (1993). This house (152 by $14 \mathrm{~m}$ ) housed 100,000 birds. There were 2 rows of support posts parallel to the long axis of the house, with the posts within each row separated by $2.9 \mathrm{~m}$. Exhaust fans were centered on the long axes (sides) of the house as at the Brooksville site, and air was drawn in through evaporative cooling pads located upstairs in the walls along the short axes (ends) of the house. This arrangement created regions of relatively still air downstairs at both ends and in the center of the house. In contrast to the Brooksville houses, there were no curtains in the manure pit to direct airflow over the manure.

Sampling at Zephyrhills was conducted on 4 consecutive weeks beginning 15 July 1995. Spot cards were placed on the upwind and downwind sides of 12 posts within the north row of posts on the 1st sampling date and spaced 7.6, 19.8, 32.0, 44.2, 56.4, and $68.6 \mathrm{~m}$ from the longitudinal center of the house in both directions (every 4th post, beginning with the 5 th post from each end of the house). White sticky cards (13 by $8 \mathrm{~cm}$ ) (Olson Products, Medina, $\mathrm{OH}$ ) were initially placed on corresponding posts in the south row. The sticky cards and spot cards were attached by no. 2 Bulldog clips (Hunt, Statesville, NC) to posts $0.5 \mathrm{~m}$ above floor level. The cards were alternated in the subsequent $3 \mathrm{wk}$ so that both rows (north and south) were sampled twice by both methods (spot cards and 

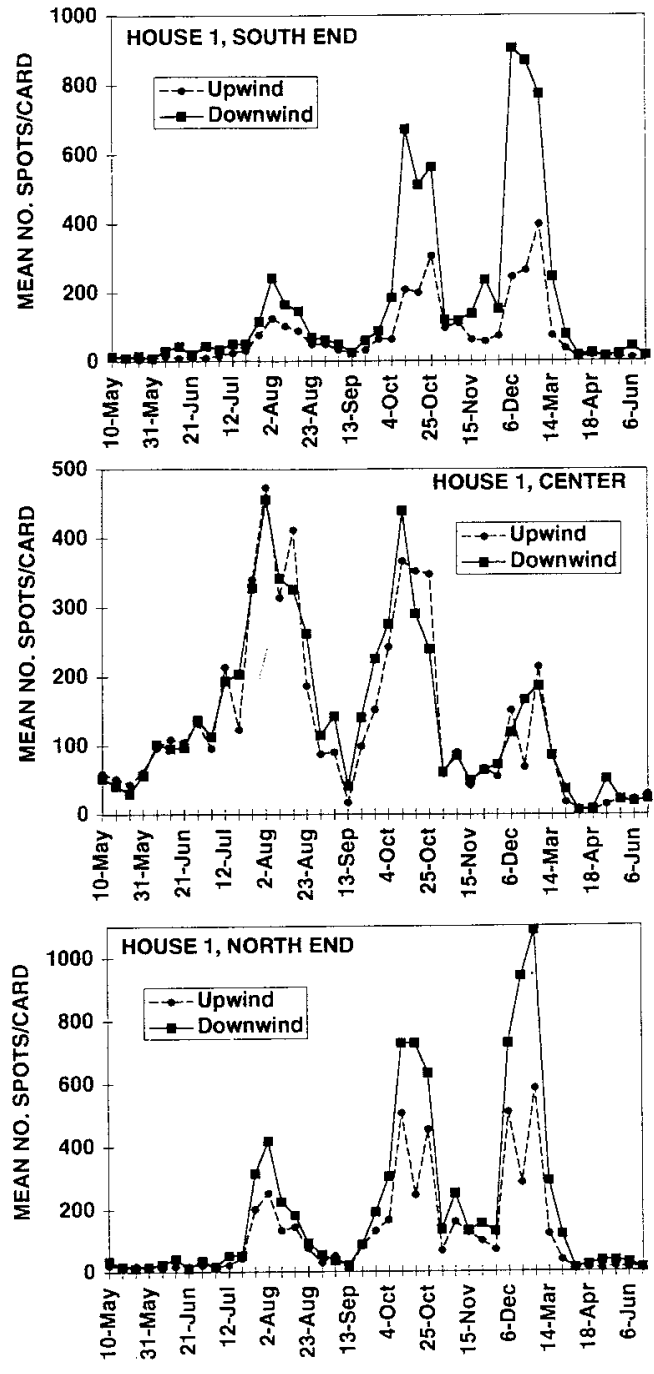

DATE

Fig. 1. Fly counts on spot cards on upwind and downwind sides of support posts in manure pit of caged-layer house 1, Brooksville, FL, 1994-1995.

sticky cards). Spot cards were left in place for $7 \mathrm{~d}$, and the number of spots was counted. Sticky cards were left for $24 \mathrm{~h}$, and the flies were identified and counted. Fly populations at both study sites consisted almost exclusively of house flies, with small numbers of $\mathrm{Hy}$ drotaea spp. present as well. The 1st d of each 7-d spot card sampling period coincided with each 24-h sticky card sampling period. Spot card and sticky card counts were analyzed by the general linear models procedure of SAS (SAS Institute 1987) using orientation to airflow, distance from center, and ends of the house as fixed main effects. Regression analysis (SAS Institute 1987) was used to compare fly counts from the 2 sampling methods.
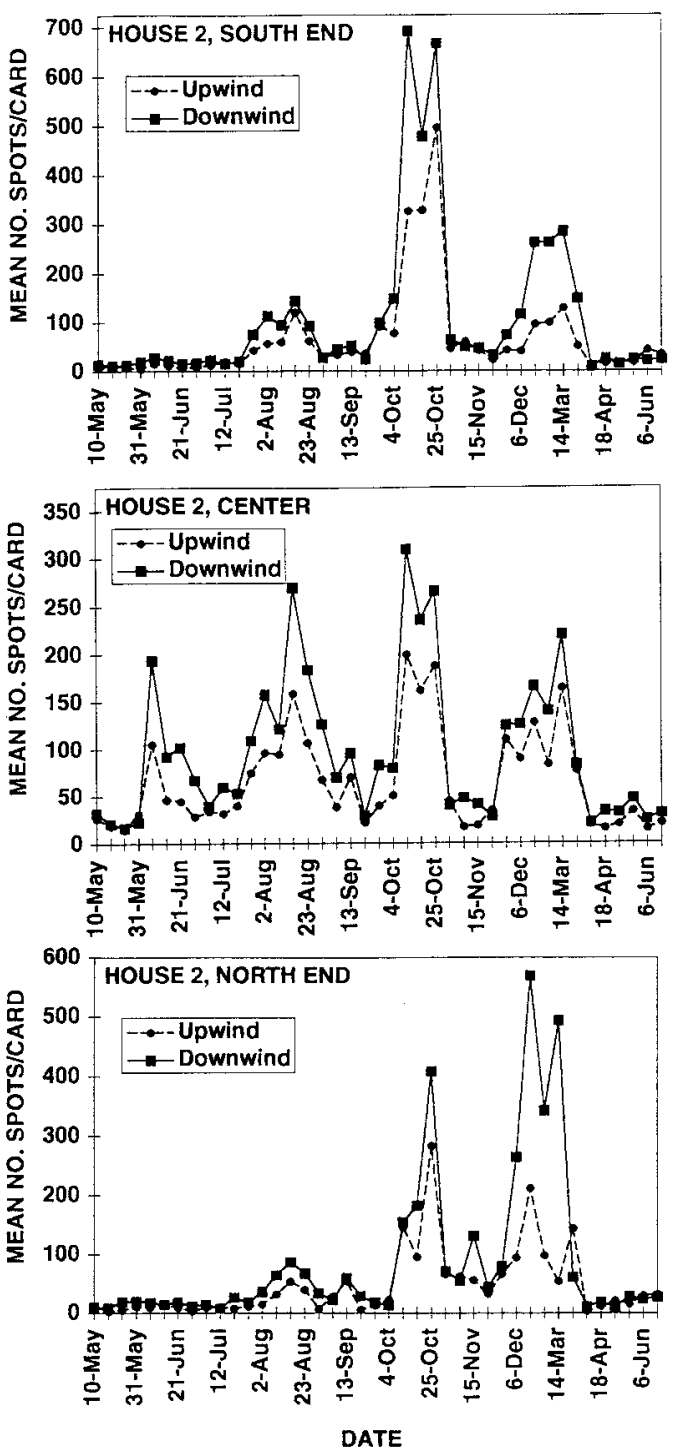

Fig. 2. Fly counts on spot cards on upwind and downwind sides of support posts in manure pit of caged-layer house 2, Brooksville, FL, 1994-1995.

\section{Results and Discussion}

Spot card counts at the Brooksville farm were about twice as high on the downwind as on the upwind sides of posts in the end blocks of both houses (Table 1; Figs. 1 and 2). Counts on upwind versus downwind sides in the center block were comparatively closer in house 2 (66.0 versus 98.6 ), and were not significantly different $(P=0.05)$ in one of the houses. This finding may be caused by the comparatively low air movement in the center of the houses compared with the ends, where air velocity is greater.

Sample date contributed significantly to the ANOVA in all blocks, and the orientation $\times$ date interaction was significant in several instances, sug- 
Table 2. House fly counts on upwind and downwind sides of posts at varying distances from the center of a poultry house near Zephyrhills, FL

\begin{tabular}{|c|c|c|c|c|c|}
\hline \multirow[t]{2}{*}{ End of house } & \multirow{2}{*}{$\begin{array}{l}\text { Distance from } \\
\text { center, } m\end{array}$} & \multicolumn{2}{|c|}{$\begin{array}{l}\text { Mean (SE) no. spots/card/wk } \\
\text { at position relative to airflow }\end{array}$} & \multicolumn{2}{|c|}{$\begin{array}{c}\text { Mean (SE) no. flies/sticky card at } \\
\text { position relative to airflow }\end{array}$} \\
\hline & & Upwind & Downwind & Upwind & Downwind \\
\hline East & 7.6 & $193.0(15.93)$ & $322.0(53.58)$ & $84.5(26.20)$ & $135.5(16.83)$ \\
\hline East & 19.8 & $170.5(16.84)$ & $257.0(63.69)$ & $57.5(8.58)$ & $127.5(11.09)$ \\
\hline East & 32.0 & $218.5(24.96)$ & $232.5(52.42)$ & $67.0(12.37)$ & $111.5(20.61)$ \\
\hline East & 44.2 & $177.5(16.66)$ & $236.5(58.11)$ & $40.5(8.30)$ & $85.0(21.39)$ \\
\hline East & 56.4 & $181.0(4.20)$ & $255.0(69.25)$ & $55.5(7.80)$ & $82.5(23.99)$ \\
\hline East & 68.6 & $272.0(44.4)$ & $362.0(104.37)$ & $82.5(17.56)$ & $133.0(11.09)$ \\
\hline West & 7.6 & $330.5(76.05)$ & $416.0(35.14)$ & $92.7(16.90)$ & $158.7(14.25)$ \\
\hline West & 19.8 & $263.0(33.07)$ & $308.5(57.59)$ & $69.5(7.97)$ & $142.5(7.37)$ \\
\hline West & 32.0 & $178.5(47.08)$ & $214.0(18.67)$ & $47.0(12.37)$ & $78.0(3.56)$ \\
\hline West & 44.2 & $84.5(31.95)$ & $228.0(25.99)$ & $60.0(8.91)$ & $51.0(8.39)$ \\
\hline West & 56.4 & $255.0(69.25)$ & $328.5(47.01)$ & $82.5(23.99)$ & $134.0(12.03)$ \\
\hline West & 68.6 & $337.0(78.84)$ & $424.5(76.91)$ & $87.0(8.02)$ & $151.0(7.19)$ \\
\hline
\end{tabular}

gesting that orientation relative to airflow is affected by fly population densities. Moreover, further partitioning of the data revealed that the downwind/upwind ratio was significantly higher at high fly densities (samples whose total counts were $>100$ ) than at low densities $(F=7.40 ; \mathrm{df}=1,811 ; P<0.01)$. The reason is unclear. If flies prefer resting sites with less air turbulence, then one might expect to see more pronounced differences in counts on upwind versus downwind sides when populations are low because of reduced competition for preferred resting sites. Our results suggest that the opposite is true, with more divergence between sides occurring during times of high fly activity. Fly competition for resting sites may be increased during periods of high fly densities, and this competition may result in more opportunities for the flies to become spatially redistributed.

Results at the Zephyrhills site were similar to those at Brooksville. Spot card and sticky card counts were significantly $(P<0.05)$ higher on downwind than on upwind sides of the posts (Tables 2 and 3). Airflow effects were more pronounced on the sticky cards than on the spot cards, perhaps because of a difference in the behavioral basis of these 2 sampling methods. Because flies can move on and off spot cards freely, spot card data provide an aggregate picture of overall fly activity during the time interval that cards are in place. In contrast, sticky cards primarily measure alighting behavior of flies. Our data suggest that house flies show a strong tendency to alight on the down-

Table 3. ANOVA for positional effects on house fly counts by using spot cards and sticky cards in a poultry house near Zephyrhills, FL

\begin{tabular}{|c|c|c|c|c|c|}
\hline \multirow{2}{*}{ ANOVA term } & \multirow[t]{2}{*}{ df } & \multicolumn{2}{|c|}{$\begin{array}{l}\text { Spot card } \\
\text { counts }\end{array}$} & \multicolumn{2}{|c|}{$\begin{array}{l}\text { Sticky card } \\
\text { counts }\end{array}$} \\
\hline & & $F$ & $P$ & $F$ & $P$ \\
\hline Orientation to airflow & 1 & 12.09 & 0.0008 & 66.78 & 0.0001 \\
\hline Distance from center & 5 & 5.20 & 0.0004 & 9.83 & 0.0001 \\
\hline Orientation $\times$ distance & 5 & 0.36 & 0.8738 & 1.80 & 0.1239 \\
\hline End of house & 1 & 5.09 & 0.0269 & 1.39 & 0.2423 \\
\hline Orientation $\times$ end of house & 1 & 0.04 & 0.8478 & 0.01 & 0.9280 \\
\hline Distance $\times$ end of house & 5 & 1.09 & 0.3725 & 2.34 & 0.0496 \\
\hline Orient. $\times$ dist. $\times$ end (error) & 77 & - & - & - & - \\
\hline
\end{tabular}

wind sides of posts. This information could be used to improve the strategic deployment of management technologies, such as light traps or bait stations, that target the adult fly.

Fly distribution at the Zephyrhills site also showed a distinct large-scale spatial pattern, with high fly populations at both ends and in the center and comparatively lower counts in the intermediate zones (Fig. 3). This spatial pattern cannot be explained by relative humidity, lighting patterns, or air or surface temperatures, which were consistent throughout the house (J.A.H., unpublished data). Although air velocity measurements were not made, the airflow pattern in this house created relative dead air zones at the very ends and in the center of the house (i.e., in those areas where flies were most abundant).

Air velocities in houses such as those described here vary depending on spatial position, the number of fans in operation, and the size of the opening through which fresh air is drawn into the facility. Mean airspeeds at facilities similar to those used in our studies are 1.6 and $1.3 \mathrm{~m} / \mathrm{s}$ in houses with tunnel and evaporative cooling systems, respectively (C.J.G. and J.A.H., unpublished data). Further mapping of air speeds was beyond the scope of the current study, which was intended to explore whether net airflow patterns influenced the distribution of flies. Additional research is required to describe air speeds within poul-

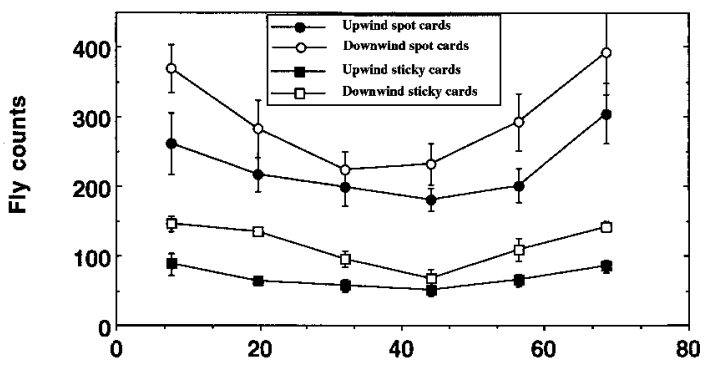

Distance from center of house (meters)

Fig. 3. Spatial distribution of house flies in the manure pit of a pullet house near Zephyrhills, FL, July-August 1995. 


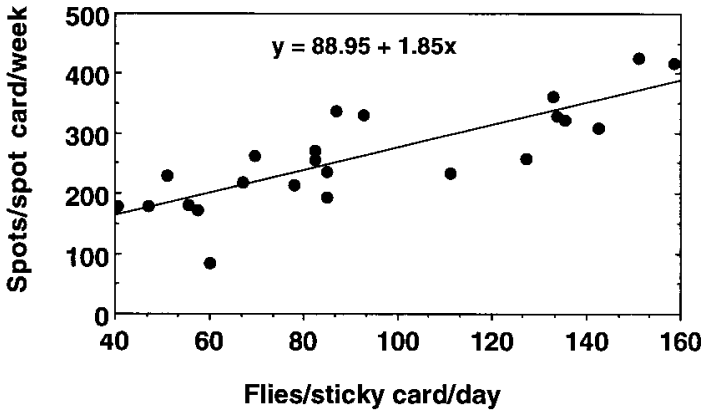

Fig. 4. Relationship between spot card and sticky card house fly counts in the manure pit of a pullet house near Zephyrhills, FL, July-August 1995.

try houses and to determine the effect of air velocity on fly behavior under controlled conditions (e.g., wind tunnels).

Sticky cards are a relatively new method for sampling house flies (Hogsette et al. 1993) that are considerably easier to deploy and collect than the sticky ribbons that historically have been used for monitoring flies (Anderson and Poorbaugh 1964, Legner et al. 1973). Results of regression analysis indicated that sticky card counts correlated well with spot card counts $\left(F=38.736 ; \mathrm{df}=1,22 ; P<0.01 ; r^{2}=0.6377\right)$ (Fig. 4). Although sampling precision may be expected to decrease at fly densities higher than spot card and sticky cards can accommodate, these 2 sampling methods correlated well over the range of moderate fly densities observed in this study.

Both sampling methods have advantages. Spot cards are easy to use and can be left in the field for varying lengths of time at the convenience of the investigator (Axtell 1970). They do not, however, allow for discrimination among different species of flies, and the same fly population produces varying numbers of spots depending on temperature (Lysyk and Axtell 1985) and nutritional status (Howard 1911). In contrast, sticky cards must be removed relatively soon after placement or they become coated with dust (Lysyk and Axtell 1986), and fly cadavers on the cards can be consumed by scavengers such as litter beetles or rodents (J.A.H., unpublished data). The chief advantage of sticky cards is that they can provide rapid information on the relative densities, sex ratios, parity, and physiological age of house flies as well as other fly species such as Hydrotaea spp. (Hogsette et al. 1993). Sticky cards also have the advantage of sampling each fly a single time (when it alights), whereas spot cards measure cumulative fly activity in the area.

These results document that airflow has a substantial impact on the spatial distribution of flies in enclosed modern poultry houses with tunnel and evaporative cooling ventilation systems. Thus, it should be possible to improve the efficiency of fly monitoring and suppression efforts in enclosed animal confinement facilities that have well-defined airflow patterns.

\section{Acknowledgments}

We thank J. Thomas, M. Miller, and G. Langley for helping with the field work and fly counts, and T. J. Lysyk, R. C. Axtell, D. W. Watson, and D. L. Kline for reviewing an early draft of this article.

\section{References Cited}

Axtell, R. C. 1970. Integrated fly control program for cagedpoultry houses. J. Econ. Entomol. 63: 400-405.

Anderson, J. R., and J. H. Poorbaugh. 1964. Observations on the ethology and ecology of various Diptera associated with northern California poultry ranches. J. Med. Entomol. 1: 131-147.

Beck, A. F., and E. C. Turner, Jr. 1985. A comparison of five house-fly (Diptera: Muscidae) population monitoring techniques. J. Med. Entomol. 22: 346-348.

Burg, J. G., and R. C. Axtell. 1984. Monitoring house fly, Musca domestica (Diptera: Muscidae), populations in caged-layer poultry houses using a baited jug trap. Environ. Entomol. 13: 1083-1090.

Driggers, D. P. 1971. Field evaluation of blacklight electrocutor grid traps for the control of flies associated with poultry. M.S. thesis, University of Florida, Gainesville.

Geden, C. J., D. C. Steinkraus, R. W. Miller, and D. A. Rutz. 1992. Suppression of house flies on New York and Maryland dairies using Muscidifurax raptor in an integrated management program. Environ. Entomol. 21: 1419-1426.

Hogsette, J. A., R. D. Jacobs, and R. W. Miller. 1993. The sticky card: device for studying the distribution of adult house fly (Diptera: Muscidae) populations in closed poultry houses. J. Econ. Entomol. 86: 450-454.

Howard, L. O. 1911. The house fly-disease carrier. Stokes, New York.

Legner, E. F., W. R. Bowden, W. D. McKeen, W. F. Rooney, and R. F. Hobza. 1973. Inverse relationship between mass of breeding habitat and synanthropic fly emergence and the measurement of population densities with sticky tapes in California inland valleys. Environ. Entomol. 2: 199-205.

Lysyk, T. J., and R. C. Axtell. 1985. Comparison of baited jug-trap and spot cards for sampling house fly, Musca domestica (Diptera: Muscidae), populations in poultry houses. Environ. Entomol. 14: 814-819.

1986. Field evaluations of three methods for monitoring populations of house flies (Musca domestica) (Diptera: Muscidae) and other filth breeding flies in three types of poultry housing systems. J. Econ. Entomol. 79: 144-151.

SAS Institute. 1987. SAS users guide: statistics. SAS Institute, Cary, NC.

Sokal, R. R., and F. J. Rohlf. 1981. Biometry. Freeman, New York.

Stafford, K. C. III, C. H. Collison, and J. G. Burg. 1988. House fly (Diptera; Muscidae) monitoring method comparisons and seasonal trends in environmentally controlled high-rise, caged-layer poultry houses. J. Econ. Entomol. 81: 1426-1430.

Received for publication 31 August 1998; accepted 9 December 1998 